\title{
ESPAÇO URBANO: DO ACESSO PELOS DIREITOS FORMAIS À COERÇÃO VELADA DA PARTICIPAÇÃO POLIITICA FEMININA ${ }^{1}$
}

\author{
Urban space: about the access for the formal rights to \\ the guarded coercion of the feminine politic participation
}

\author{
Almir NABOZNY2
}

\begin{abstract}
RESUMO
Este artigo discute as relações sociais de gênero e a produção de espaço, evidenciando a discussão sobre a participação política feminina como forma de pressão ao direito de acesso à cidade. Dissertando sobre os diferentes papéis sociais das mulheres, sua inserção e participação na política, o artigo está dividido em quatro partes. Após uma breve introdução à temática, segue uma aproximação das sujeitas, ou seja, referencia-se a base metodológica da parte empírica que deu origem a este artigo. As relações sociais femininas, seus potenciais e limites são ilustrados através de citações provindas da empiria sobre a participação de mulheres no Orçamento Participativo na cidade de Ponta Grossa/PR. A parte seguinte aborda a questão desse envolvimento político das mulheres diante dos seus papéis de gênero assumidos e construídos socialmente. As considerações finais enfatizam essa interiorização, que influencia a atuação das mulheres tanto no espaço público como no privado.
\end{abstract}

Palavras-chave:

Espaço; gênero; participação política.

\begin{abstract}
This article discusses the social relations of gender and production of space, with emphasion the female political participation as a way to push access to the city. It is discoursing on the women in different social roles in their insertion and participation in politics, this article is divided in four parts. After a brief introduction to the theme, follows an object approximation, the methodological base is based on empiric work, which is the origin of the article. The female social relations, their potentials and limits are illustrated by quotations from the empiricism about the woman participation in the "Orçamento Participativo" (Participative Budget) in the city of Ponta Grossa, state of Paraná (Brazil). The following part presents the political development by women front of their roles of gender assumed and constructed socially. The last considerations are an emphasis on this introspection that influences the female actuation in public and private space.
\end{abstract}

Key words:

Space; gender; politics participation.

1 Trabalho desempenhado com a orientação da Profa. Dra. Joseli Maria Silva (UEPG - PR), a quem endereçamos sinceros agradecimentos. Gratos também às considerações efetivadas pelos pareceristas da revista.

2 Geógrafo e professor de Geografia. Discente do Programa de Pós-graduação em Geografia. Mestrado em Gestão do Território na Universidade Estadual de Ponta Grossa (UEPG). (almirnabozny@yahoo.com.br) 
NABOZNY, A. Espaço urbano: do acesso pelos direitos formais à correção velada...

\section{INTRODUÇÃO}

Em relação às fronteiras sexuais pós-século XIX, assim se manifestou Michaelle Perrot:

\begin{abstract}
Estas fronteiras movem-se singularmente. A tendência é primeiramente aquela de uma segregação crescente e de uma nova ritualização sexual do espaço; mas democratização e efeito de massa tendem sempre a transbordá-las. Aliás, nítidas diferenças opõem burgueses e populares. Desta geografia flutuante, nós só podemos desenhar aqui algumas curvas de nível. (PERROT, 2001, p. 16)
\end{abstract}

Em termos constitucionais, todos os cidadãos, independentemente do sexo, possuem direitos iguais perante o Estado brasileiro. Assim, o sistema legal garante a igualdade formal para homens e mulheres. Entretanto, a sociedade fundamenta-se também por relações de outras naturezas, e o significado das palavras que nomeiam corpos é apropriado e utilizado de formas muito diferentes daquelas constituídas na esfera jurídica. Os corpos classificados, através da perspectiva biológica, em machos e fêmeas devem atuar como homens e mulheres, desempenhando papéis sociais masculinos e femininos. Esses papéis não se desenvolvem apenas a partir de aparatos legais, mas são interiorizados na ação cotidiana e, sendo assim, estão enraizados nos mais sutis comportamentos humanos, inclusive no direcionamento do desejo heterossexual.

Compreender a relação do desempenho de papéis sociais femininos e masculinos e o espaço geográfico é o objetivo deste artigo, que explora as intersecções do espaço privado e do público na construção da luta pelo acesso das mulheres ao direito da cidade.

Para cumprir com os ensejos relacionados, este artigo está lastreado por dados empíricos decorrentes de pesquisa realizada junto ao Grupo de Estudos Territoriais (GETE/UEPG), no qual vários pesquisadores têm versado sobre discussões de gênero e espaço geográfico. Primeiramente são discutidos os papéis sociais de gênero enquanto potencialidades e, paradoxalmente, limite para inserção política feminina. Num segundo momento, dissertamos sobre as características da participação cidadã. Nesse sentido, este trabalho realiza um estudo sobre a produção do espaço urbano, evidencia a relação de reprodução da pobreza das famílias monoparentais chefiadas por mulheres, demonstrando suas fragilidades, no tocante ao campo de intervenção política, por outro lado contrariando estudos generalizantes que meramente localizam as mulheres como vítimas, pautando-nos numa concepção ampla de política, abordando o cotidiano (no qual a realidade é interpretada e atribuída de sentido), revelando um universo feminino potencial para ser explorado que pode transgredir a ordem hegemônica e neutralizar a crescente exclusão social das mulheres e viabilizar sua luta no processo contra reprodução da pobreza.

\section{APROXIMANDO-SE DAS SUJEITAS}

O espaço urbano, segundo Corrêa (2003a), é fragmentado, articulado, reflexo, condicionante social, repleto de símbolos e campos de lutas, cuja produção se dá pela ação dos agentes produtores, segundo as seguintes categorias: os proprietários dos meios de produção, proprietários fundiários, promotores imobiliários, o Estado e os grupos sociais excluídos. Os agentes atuam simultaneamente de forma contraditória e complementar, pois seguem a lógica capitalista que busca o lucro e a apropriação privada da terra urbana, mas ao mesmo tempo possuem interesses específicos.

O espaço urbano é um campo de lutas sociais estabelecido entre diferentes grupos que, através do desempenho político, conseguem alocar seus interesses na esfera institucional do Estado. A temática da produção do espaço urbano, comum no âmbito da perspectiva marxista, é, neste trabalho, ampliada pela incorporação das relações de gênero no processo de produção da cidade. Cosgrove (1999) sustenta a idéia de que vários outros elementos devem ser contemplados na análise espacial, além das relações de classe e de acumulação de capital. A produção do espaço realizada por agentes socioculturais não se restringe à relação dialética de reflexo e condição, mas, sobretudo, amplia-se no processo de transformação. Essa perspectiva ocorre porque as práticas sociais são resignificadas pelos sujeitos, criando, portanto, um campo de possibilidades da criação de novos elementos, que operam sustentáculos ao próprio movimento de criação e manutenção do espaço, numa indissociável composição de um modo total de vida.

Corrêa (1995), ao analisar a compreensão da cultura e o espaço, evidencia que para a compreensão geográfica se contemplem tanto os componentes materiais como os sociais, intelectuais e simbólicos. Apesar das possibilidades abertas pela corrente da Nova Geografia Cultural, houve poucos avanços na superação do discurso masculino hegemônico na ciência geográfica. Referendamo-nos em Mignolo (2004), que ressalta as perspectivas branca, masculina e européia, enquanto constantes de uma hegemonia no discurso científico como um todo. Porém, Mignolo (2004) vislumbra um importante e jovem olhar que vem contribuindo nas discussões do conhecimento, esses amparados pela crítica anticolonial, étnica 
e feminista nas ciências, ainda que esses movimentos venham ganhando visibilidade na(s) geografia(s) produzida(s) nos países de capitalismo central e em outros campos do saber no Brasil, tais como a história e a sociologia, entre outros, e os próprios movimentos sociais; houve pouca permeabilidade das inscrições de gênero na Geografia Brasileira. Algumas importantes geógrafas, independente da nacionalidade, têm lutado para fortalecer a perspectiva de gênero. Entre elas, destacamos Rose (1993), McDowell (1999) e Silva (2005), havendo uma luta científica para que as mulheres sejam reconhecidas como significativas produtoras do espaço urbano. Por exemplo, Silva (2005) discute a proposta teórica de Rose (1993), trazendo para o debate da Geografia brasileira o conceito de "espaço paradoxal" como uma possibilidade de subversão da construção masculina do conhecimento geográfico. $\mathrm{O}$ espaço paradoxal como um espaço de luta.

Um primeiro desafio para a geografia urbana "feminista" foi o de tornar as mulheres visíveis. O que levantou, de acordo com Smith (1996), questões relacionadas ao lugar da mulher na divisão social do trabalho, as dificuldades femininas em acessar o que é produzido pelo urbano e a contestação do preconceito contra lares "não-familiares", ou seja, encabeçados por mulheres com pouca probabilidade de reprodução das estruturas patriarcais que estão relacionadas ao núcleo familiar tradicional. Ao abordar questões atinentes ao gênero, Butler (2003) atesta no intuito de considerar o feminino no plural, ou seja, o ser mulher, entre outros, está vinculado a uma teia relacional de classe, sexualidade, religião e assim por diante, o que compõe as múltiplas identidades. É nesse sentido que Silva (2003), ao explorar as potencialidades do conceito de gênero e geografia, aponta a dificuldade de delimitação de fronteiras do objeto de estudo.

Do total dos domicílios particulares permanentes do espaço urbano de Ponta Grossa (PR), conforme os dados do Censo IBGE (2000), 23,97\% são chefiados por mulheres. Destes, $63,5 \%$ possuem rendimento familiar igual ou inferior a três salários mínimos. Um essencial aspecto na luta contra a condição socioespacial de pobreza é a política, a fim de alocar interesses na arena do Estado.

Para iniciar a investigação que resulta neste artigo, buscaram-se locais expressivos da presença de lares chefiados por mulheres, já explorados em outra perspectiva por Prochner (2005). Foram selecionados o Condomínio Social PAI, o Conjunto Habitacional Rio Pitangui III e o Loteamento Rio Pitangui IV. Para investi- gação do grupo focal, foram realizadas entrevistas semiestruturadas com pessoas componentes do mesmo, que estabelecido pelos integrantes do Grupo de Estudos Territoriais (GETE/UEPG) do qual faço parte. A pessoa entrevistada deveria ser do sexo feminino, se identificar como responsável pelo domicílio, possuir uma renda igual ou inferior a dois salários mínimos, escolaridade de no máximo Ensino Fundamental completo e possuir sob sua tutela filhos com idade igual ou inferior a 14 anos. A opção e construção metodológica de analisar um grupo focal estão imbuídas na consideração da diversidade das identidades femininas, em o ser mulher constituir-se no agir temporal e espacial. Dessa forma, não é possível tecermos afirmativas fora da escala geográfica de análise, a dimensão cotidiana e de grupo.

Na construção metodológica da pesquisa, não se definiu um percentual amostral, mas se optou por aplicar um critério conhecido como "saturação". Essa abordagem é comum para os pesquisadores de ciências sociais. Trata-se da possibilidade de

(...) chegar a esse número-limite (não definido previamente) no decorrer da pesquisa: quando os temas e/ou argumentos começam a se repetir isto significaria que entrevistar uma maior quantidade de outros sujeitos pouco acrescentaria de significativo ao conteúdo (...). (SÁ, 1998, p. 92)

Embora haja uma limitação de grupos minoritários à participação no Estado, houve importante experiência de participação popular na organização das finanças públicas, promovida em Ponta Grossa/PR através da instituição do Orçamento Participativo (OP) durante o período 2001-2004. Assim, esse evento foi também alvo dessa pesquisa, que contou com a investigação da ação das mulheres delegadas e conselheiras do OP.

Todas as entrevistas realizadas foram gravadas e os seus respectivos conteúdos transcritos na íntegra para posteriormente se sistematizar as informações. Os dados transcritos foram trabalhados de forma qualitativa através do agrupamento das respostas das respectivas perguntas por categorias criadas também em função do retorno às interrogações, e finalmente de forma quantitativa ao atribuirmos números e porcentagens aos símbolos verbais aglutinados em conjuntos.

Portanto, todas as porcentagens apresentadas neste artigo são relativas ao percentual de evocações de 12 mulheres chefes de família e 12 militantes do Orçamento Participativo. Tendo em vista que não se trabalhou com amostras prévias, o número 12 para os dois grupos foi uma coincidência, caracterizou-se por ser um 
NABOZNY, A. Espaço urbano: do acesso pelos direitos formais à correção velada...

momento quando as respostas tornaram-se saturadas, ou seja, orbitavam em torno de núcleos centrais. Essa saturação é confiável em função das vozes das sujeitas serem despidas de conceituações prévias, somando-se a triangulação ${ }^{3}$ desses discursos a dados quantitativos verificados no Censo IBGE (2000).

\section{A INTERIORIZAÇÃO DOS PAPÉIS DE GÊNERO: LIMITES E POTENCIALIDADES DAS RELAÇÕES COTIDIANAS NOS ESPAÇOS PÚBLICO E PRIVADO}

Os papéis de gênero não compõem quadros monocromáticos, mas são constituídos de muitos tons sobrepostos de homens e mulheres diversos, transpassados por etnia, renda, religiosidade, entre outro aspectos. Duncan e Duncan (1999) afirmam que a cultura é complexa, composta de grupos e elementos "fragmentados, altamente contestados, freqüentemente híbridos e sempre fluidos" (DUNCAN; DUNCAN, 1999, p. 64). Nesse sentido, dificilmente encontram-se padrões repetitivos, mas uma realidade sempre transformada no desenrolar das relações.

O gênero é constituído de forma relacional e processual, conforme Silva (2005). O papel masculino, nesse sentido, se constitui na relação com o feminino. No universo tomado como base para este artigo, constatou-se que o papel masculino desejado por $100 \%$ das mulheres entrevistadas é o de provedor da família e a metade delas acredita que o papel feminino na sociedade é ser responsável pela manutenção do bem estar familiar, relegando o trabalho no espaço público a um segundo plano. Suas funções primordiais são: limpar, cuidar dos filhos, cozinhar e entregar o corpo ao provedor material do clã familiar como retribuição pelo sustento. Assim, pode-se constatar que para este grupo focal há uma definição clara das fronteiras dos campos de atuação dos papéis de gênero, no qual o papel feminino desempenha, em geral, trabalho não pago. Embora possa haver permeabilidades desses desejos em vários estratos sociais a pluralidade das identidades femininas são como aspectos referendados na análise do grupo focal específico.

Do total de evocações na avaliação da vida conjugal; $53 \%$ foram relativas ao controle do corpo feminino pelo ser masculino, envolvendo tipos permitidos de vestuário, horários e locais de mobilidade; $23 \%$ das evocações foram relativas à segurança representada pela presença masculina no grupo familiar, relacionando questões positivas como preservação moral e patrimonial; já $19 \%$ evoca a preocupação masculina com a saúde do grupo familiar; e, por fim, apenas $5 \%$ relatam temas com relação a empreendimentos futuros compartilhados. O controle do corpo, não só em termos quantitativos, mas na ordem em que é citado, emerge como representação central da experiência entre os gêneros feminino e masculino.

Durante o decorrer das entrevistas, o tema sobre o controle do corpo feminino pelos homens era uma característica constante. No roteiro de entrevista havia questões similares, porém com diferentes abordagens de articulação dos signos verbais e, novamente, o tema tornava-se central. Em 54\% há um controle explícito do corpo feminino pelo sujeito masculino, com proibições e declarações verbais e de uso da força física; $37 \%$ das evocações sobre o controle do corpo demonstram resignação, pois o controle é interiorizado pelas muIheres, promovendo um processo de auto-regulação ancorada no padrão social. Somente $9 \%$ das entrevistadas afirmam não haver controle por parte dos sujeitos masculinos.

Essas relações de gênero internalizadas demonstram a complexidade da realidade, e a ciência, conforme Morin (1996), deve se interessar "pelo que está escondido por trás dos fenômenos" (MORIN, 1996, p. 17). Dois excelentes artigos se propuseram a discutir relações de gênero sob a égide das táticas femininas, que sustentam os fenômenos. Anyon (1990) argumenta que as mulheres resistem, por outro lado, internalizam e aceitam as "ideologias estereotipadas". O outro artigo é de Sarti (1989), baseada no "Ensaio sobre a dádiva de Mauss", que propõe como fundamento das relações de gênero a reciprocidade "como um sistema de troca que organiza o mundo social" (SARTI, 1989, p. 39). Nosso argumento é de que se trata de um processo de construção permanentemente negociado, através de um contrato espacial e de caráter relativizado no tempo. Tanto que as transgressões não ocorrem linearmente, não é meramente causa e efeito da troca insatisfatória. Existe complementaridade e internalização, mas que se dá pela contrariedade internalizada da "auto-imagem corporal" pela mulher, quando regras tácitas e trocas se dão também entre os "iguais". Não ser motivo de comentário do "olho vigilante da vidraça vizinha" é um relato comum, conforme pode ser evidenciado a seguir em trecho de entrevista de uma senhora originária do

3 A triangulação como um recurso para a resolução do problema da validade científica, constituindo-se na utilização combinatória de diferentes técnicas e fontes a fim de fortalecer as interpretações. Versando a multiplicidade real por mais de um mecanismo metodológico, como já explorado na psicologia social por Jovchelovitch (2000). Para o artigo, triangulamos dados estruturais: Censo IBGE 2000 e entrevistas de mulheres chefes de família juntamente a ativistas do Orçamento Participativo. 
norte do país (Porto Velho/Rondônia), que afirma possuir hábitos de vestuário diferenciados da população vizinha, devido a sua origem, pois seus hábitos eram considerados "normais" no lugar de onde vinha:

Não, pra começá que sô lá de Porto Velho por causa de ser um lugar muito quente então o pessoal andava à vontade lá, mulheres de bermuda curtinha, blusinha de alça, então ele não simportava com isso não. Ele tamém já era do Ceará, né, então era tudo lugar quente, não é que nem aqui, qué coisa horrível! É, reparam em tudo, então lá eles vivem bem à vontade. 4

Longe de ressuscitar um determinismo geográfico, esse exemplo demonstra que os seres humanos vivem concretamente através de atos, valores e preferências que são constituídos de forma relacional social, temporal e espacial.

$\mathrm{Na}$ avaliação da vida sem o cônjuge (feita por muIheres chefes de família), 78\% das evocações apontam dificuldades de diversas naturezas; $58 \%$ sentem falta do cônjuge para realização de serviços domésticos (como encanamento, carpintaria, entre outros) somados às necessidades econômicas; $28 \%$ das entrevistadas relatam sentir falta da autoridade paterna para com a educação dos filhos e, por último, $14 \%$ delas sente falta de afeto. Mesmo apontando dificuldades, $58,5 \%$ das mulheres sequer admitem uma nova relação conjugal.

Muito interessante é a constatação de que 100\% das mulheres buscam um homem provedor, mas ao se casar elege o amor como elemento principal da relação. O filósofo suíço Rougemont (2003), ao estudar a história do amor no Ocidente, ilustrando com uma discussão sobre o Mito de Tristão e Isolda, atesta para a incompatibilidade entre o amor e o casamento na sociedade ocidental e a crise institucional. Para o autor, o amor do Ocidente é representado como algo buscado, mas impossível de ser vivido, e denomina esse tipo de sentimento de "amor-paixão".

"O ardor amoroso, espontâneo, vitorioso, nãocombatido é, por essência, efêmero. É uma chama que não pode sobreviver ao brilho de sua consumação." (ROUGEMONT, 2003, p. 62) Nesse sentido, o amor consumido, somado às dificuldades do não cumprimento dos papéis sociais de gênero, torna os enlaces matrimoniais da periferia urbana do grupo analisado vulneráveis.

Uma situação alarmante é o abandono total do papel paterno na realidade estudada. Em $84 \%$ das fa- mílias monoparentais, os ex-cônjuges, mas "ainda pais", não contribuem financeiramente para a manutenção dos filhos e, na maioria dos casos, o abandono econômico é somado ao afetivo. Em geral, essas mulheres sofrem ameaças por parte dos ex-companheiros quando procuram os direitos de seus filhos, a fim de receber pensão alimentícia. Diante das ameaças e do descrédito no papel do Estado, acabam desistindo e arcando sozinhas com o sustento familiar.

Em um momento de crise do Estado e escassez de recursos, investir nessas mulheres é executar uma excelente política social preventiva ao aumento da pobreza, pois, com o fim da aliança matrimonial, é sob suas tutelas que fica um grande contingente de crianças.

Em relação à atuação feminina no espaço público, notadamente na política, há uma clara vinculação do papel de gênero feminino exercido no espaço privado que extrapola para a sociedade em geral. Quando questionadas sobre as relações entre mulher e governo, apenas $20 \%$ das mulheres que participaram do Orçamento Participativo (OP) consideram que as mulheres não possuem perfil para governar e sustentam sua posição em argumentos profundamente enraizados na moral religiosa, que considera a mulher como ser inferior ao homem, ou ainda, pela sua inferioridade biológica, como pode ser evidenciado nos depoimentos que seguem:

(...) em questão de respeito, e eu acho que a mulher prejudica um poco nesta questão do respeito da (pausa) de se expor, o homem eu acho que pode se expor mais que a mulher, na minha opinião, né? Apesar que hoje em dia a mulher tá tendo voz ativa em tudo, né? Mais eu acho ainda que em questão de governá, eu acho que seria mais pros homes. Até por questão de viaje, tudo pra mulher às veiz cumplica um poco. O que atrapalha. Dê, exemplos. É a casa, filhos, os poblemas da mulher, né, que nem sempre às veiz ela tá em condição, né, pa viajá pa assumir certos compromissos. Na minha opinião, né? Não sei. (risos) “(...) Não. Não. Apesar deu ser mulher eu não concordo, (...). Eu acho administração, já, Deus já dexo pro home, sabe porquê? A Eva já, não sei se você intende da Bíblia? A Eva já é um pedaço de Adão, né, e, por Eva que nós pagamo, por todo os pecado, nóis sofremo por Eva, né, porque ela que feiz Adão pecá. (...) quem tem que administra é o home, a mulher não, a mulher tem que trabalhá, ajudá o marido, cuidá em casa, cuidá dos filho, mais partido e mulher não. Essa é minha opinião. ${ }^{5}$

4 Depoimento de uma chefe de família residente no Condomínio Social PAI - Ponta Grossa/PR.

5 Depoimento de mulheres que participaram como delegadas do Orçamento Participativo. 
NABOZNY, A. Espaço urbano: do acesso pelos direitos formais à correção velada...

Esses depoimentos demonstram posições que foram fundadas há séculos, mas que ainda têm sido alimentadas pela sociedade nos atos cotidianos. Embora longa a citação, é importante demonstrar, através de Badinter (1985), a concepção teológica da relação estabelecida entre homens e mulheres:

Primeiro ato: a criação do homem que, mal saído das mãos de Deus, dá o nome a todas as espécies animais criadas antes dele. Vendo-o decepcionado por não encontrar entre elas uma companheira que Ihe servisse, Deus o adormece, retira-lhe uma das costelas e forma em torno um tecido de carne. Assim nasceu a mulher. Segundo ato: a mulher, responsável pelo pecado, é a perda do homem. Conhecemos os discursos tentadores da serpente que prometia a Eva ser semelhante a Deus e ter o conhecimento do Bem e do Mal. Ela comeu o fruto e ofereceu-o a Adão, que não o recusou. Vendo a desobediência de suas criaturas, Deus pediu explicações a Adão, já responsável pelo casal. Este respondeu piedosamente: 'a mulher que me deste por companheira, ela me deu da árvore e comi'. Nesse incidente, a audácia, a curiosidade e a vontade de poder estavam com a mulher. Terceiro ato: as maldições. Todos sabemos de cor as duas primeiras, lançadas sobre Eva: 'multiplicarei grandemente a tua dor e a tua conceição; com dor parirás teus filhos'. Talvez tenhamos esquecidos a terceira, carregada de conseqüências durante dezenas de séculos: 'e a tua paixão será para o teu marido, e ele te dominará'. O conceito de paixão implica necessariamente as idéias de passividade, de submissão e de alienação que definem a futura condição feminina. (BADINTER, 1985, p. 33-34)

Nesse sentido, evidencia-se que a concepção teológica não é algo que paira no ar, mas é exercitada pelos atos dos sujeitos e de suas representações ancoradas em seus contextos espaciais. Oitenta por cento das conselheiras e delegadas do OP e $91 \%$ das chefes de família entrevistadas consideram que as mulheres possuem capacidade para governar.

Das entrevistadas que consideram que as mulheres possuem qualidades positivas para exercer cargos de governo, apenas $12,5 \%$ delas considera que homens e mulheres possuem iguais condições e, a maior parte, $87,5 \%$, considera que a mulher possui características diferentes das dos homens; entre elas, apontam: a intuição, a teimosia, a calma e a sensibilidade. Apenas uma vez foi evocada a capacidade intelectual feminina. Esses elementos compõem um perfil tradicionalmente atribuído às mulheres, pois, segundo Badinter (1985), a concepção de que a inteligência não é um atributo feminino está apoiada nos escritos aristotélicos, construída há século:
Quanto à cidadã, essencialmente inferior ao homem, seja qual for sua idade. Desvalorizada do ponto de vista metafísico, pois encara o princípio negativo, a matéria (contrariamente ao homem, que personifica a forma, princípio divino, sinônimo de pensamento e de inteligência), a mulher é igualmente considerada personagem secundária na concepção. Semelhante à terra que precisa ser semeada, seu único mérito é ser um bom ventre. Como é dotada de uma frágil capacidade de deliberação, o filósofo deduz logicamente que sua opinião não é digna de consideração. A única virtude moral que lhe é reconhecida era a de "vencer a dificuldade de obedecer". Sua honra residia num "modesto silêncio". (BADINTER, 1985, p. 32)

Ao mesmo tempo em que interiorizaram o papel instituído historicamente, considerando-se "teimosas", essas mulheres resignificam o elemento e consideram a "teimosia" um caráter positivo da constituição da feminilidade e uma diferença com relação ao masculino.

Embora reconheçam o potencial feminino de liderança, elas votam em representantes masculinos. O fato é que a incorporação dos papéis de gênero apresenta seu caráter paradoxal, na medida em que, simultaneamente, limita a participação política feminina e também constitui um aglutinador de potencialidades femininas de crítica e ação nos espaços cotidianos.

\section{AS CARACTERÍSTICAS DA PARTICIPAÇÃO POLÍTICA FEMININA E A PRESSÃO AO DIREITO À CIDADE}

A interiorização dos papéis de gênero ocorre de forma sutil, mas sua exteriorização pode ser visibilizada com facilidade nas relações que essas mulheres estabelecem nos espaços públicos e privados. Indubitavelmente, elas priorizam a organização e a manutenção das relações do espaço privado. É nessa escala de ação que gastam a maior parte de sua energia e se sentem reconhecidas, mesmo que saibam que a luta ao direito da cidade depende de uma ação que extrapole as fronteiras do espaço privado. Em meio a esse âmago, a análise do espaço urbano, a partir do vislumbrar da ação dos agentes produtores e seus interesses ligados à ação capitalista que busca o lucro e a apropriação privada da terra urbana, perpassa ao acréscimo de outras dimensões que compõem a totalidade espacial. Assim, a cultura, em que se arranja simultaneamente o político e o econômico, que não são dimensões puras, mas se interconectam as heterotopias constituintes da pluralidade da realidade (CORRÊA, 2003b). Há muitos caminhos possíveis de inter-relação entre o objetivo e o subjetivo e, nesse sentido, múltiplos significados que dão sentido à vida cotidiana são produzidos por grupos sociais em seus 
contextos históricos e espaciais específicos arraigados às performances de gênero.

Ao serem interrogados sobre as dificuldades encontradas na atuação política das mulheres componentes da estrutura do Orçamento Participativo, elas relatam, na maioria, que não há dificuldades. Esse posicionamento, num primeiro momento, é animador. Entretanto, ao se aprofundar os questionamentos sobre o tema, constatou-se que a não dificuldade atual é resultado de um contexto específico: essas mulheres "já cumpriram com sua obrigação como mães". Ou seja, só conseguem atuar politicamente a partir de uma faixa etária e com filhos crescidos que não mais exige delas o cumprimento do principal papel feminino: "o de ser mãe". As mulheres secundarizam sua atuação política porque a centralidade da vida feminina está calcada no desempenho do papel materno no espaço privado. Por ora, é de relevância que as mulheres inseridas no espaço do Orçamento são sujeitas ocupantes de postos não habituais do cosmos feminino.

Já as mulheres chefes de família têm inúmeras dificuldades para atuarem na luta política, pois, além de serem as únicas responsáveis pelo sustento da família, arcam sozinhas com o processo educacional. Giddens (1996) afirma que essas mulheres são pioneiras na organização de novos padrões familiares e redes de parentesco, já que possuem uma condição de vida particular. Prochner (2005) alerta sobre a condição feminina de responsáveis pela família e, ao mesmo tempo, habitantes de áreas periféricas, com baixa qualidade de serviços públicos. Essa conjugação de fatores faz com que elas criem redes de base comunitária para sua sobrevivência e de seus filhos, envolvendo vizinhos e parentes como mães e filhas(os) mais velhas(os). Gottdiener (1993), ao atentar para produção social do espaço urbano, focaliza a análise na estrutura e na ação onde se destaca o espaço como um produto co-determinado processualmente na produção total de vida. A estrutura restringe as possibilidades de ações dessas mulheres, ao mesmo tempo que potencializa arranjos permeados pelas características de subjetividade, simbólicas e culturais, em que se produz e inova o espaço urbano.

A atuação política não é uma prioridade para a maioria das mulheres investigadas, tal qual também evidenciando por Ribeiro (2000) ao estudar o Orçamento Participativo na cidade de Santo André/SP. Segundo a autora, a participação política feminina ocorre quando elas estão mais velhas e com os filhos já criados: "Exatamente no período que podem desvencilhar-se um pouco dos afazeres domésticos e responsabilidades familiares, que se somam à inserção política." (RIBEIRO, 2000, p. 79)
Quando elas atuam no espaço público, aproveitam de sua experiência no espaço privado e lutam para modificá-lo. Na experiência do Orçamento Participativo em Ponta Grossa, foi a presença das mulheres que possibilitou várias conquistas na periferia da cidade. É justamente a experiência feminina no processo de reprodução familiar que coloca a mulher no papel paradoxal de possuir vantagens para apontar as necessidades sociais, por um lado, e, por outro, manter-se consumida pelo papel materno e de dona de casa, além de provedora da família. Reforçamos a perspectiva de "Espaço Paradoxal" (ROSE, 1993) em que se contempla a plurilocalização dos sujeitos, conforme as configurações de forças estabelecidas através do espaço e do tempo, simultaneamente num embate entre centro e periferia das múltiplas orquestrações possíveis. Ao realizar esses diversos papéis, os

\section{(...) sujeitos sociais revelam muito mais do que visões idiossincráticas quando se expressam; sua experiência não está deslocada da experiência de sua sociedade (...) é precisamente do conjunto multifacetado de ex- periências únicas que a totalidade da realidade social emerge. (JOVCHELOVITCH, 2000, p. 113)}

A compreensão de que a política é parte integrante de sua vida plena como cidadãs é ainda frágil. Cem por cento das mulheres que fizeram parte da estrutura organizacional do Orçamento Participativo reconhecem a importância da política na vida cotidiana, mas em $60 \%$ dos casos não conseguiram citar um exemplo concreto, evidenciando uma fragmentação da esfera política e de sua experiência diária. Os outros $40 \%$ das mulheres que conseguiram elaborar exemplos concretos trouxeram para a reflexão o bairro, apontando fatores de demanda de escolas e postos de saúde. Desse grupo de $40 \%$, em $75 \%$ ao reconhecimento na escala do bairro e apenas $25 \%$ constata que a política influencia na totalidade de suas vidas.

Em relação ao grupo de mulheres chefes de família investigado, o reconhecimento da importância da política em sua vida cotidiana é da ordem de $67 \%$, e os outros $33 \%$ que não a reconhecem justificam que política e religião não se discutem, revelando uma legitimação de um "poder natural", distante e inacessível ao cidadão comum.

A escolha do candidato nos pleitos eleitorais baseia-se nas experiências cotidianas. Para $50 \%$ das entrevistadas, o fator principal de escolha é a verificação do passado empreendedor; para $30 \%$, os elementos principais de escolha são os aspectos pessoais de caráter; e em apenas $20 \%$ dos casos as mulheres escolhem o candidato pelas propostas de governo. Esse 
aspecto resulta numa maior dificuldade de renovação do quadro político, já que novos candidatos não possuem uma trajetória explícita na política partidária, como é o caso de candidatas mulheres que tenham recentemente adentrado com maior expressividade nas disputas eleitorais. Assim, a inexpressiva participação feminina no quadro da política partidária em Ponta Grossa pode ser agravada, contribuindo para a reprodução da hegemonia masculina.

Além da dificuldade em sistematizar seu projeto social, alia-se a descrença da seriedade na condução política do país. De acordo com Jovchelovitch, a corrupção e a impunidade são velhas questões, a sua naturalização na vida quotidiana é um sintoma do poder que detém como padrão do comportamento social" (JOVCHELOVITCH, 2000, p. 26). Nesse sentido, essas mulheres, descrentes na seriedade política, acreditam apenas naquilo que podem comprovar a partir de sua própria experiência, arraigada em suas espacialidades cotidianas.

Quando questionadas sobre a importância do partido político para decidir em quem votar, apenas $20 \%$ das entrevistadas consideraram esse um elemento importante. As entrevistadas que consideram importante a vinculação do candidato ao partido possuem filiação ao Partido dos Trabalhadores (PT). A maioria, $80 \%$ das respostas, considera que o partido não é um elemento importante na escolha do candidato e que o que importa é a "pessoa" do candidato, não realizando nenhuma vinculação deste aos posicionamentos ideológicos dos partidos.

Essas características são importantes na medida em que o compromisso entre o eleitor e o candidato não se efetiva quando se vota apenas na "pessoa" e não no "contrato" que ele representa, ou seja, o projeto social que o partido constrói na disputa nos pleitos eleitorais. O carisma do candidato torna-se mais importante do que seu projeto de sociedade. Pode-se compreender assim a satisfação das pessoas entrevistadas em se autodenominarem como "conhecidas", ou "amigas" dos candidatos, sentindo seu voto recompensado nesse reconhecimento.

Constatou-se que o perfil apresentado pelas muIheres chefes de família é o mesmo das participantes do OP no que diz respeito aos elementos de escolha dos candidatos nos pleitos eleitorais. Uma única diferença foi evidenciada na simpatia apresentada pelo Partido do Movimento Democrático Brasileiro (PMDB), mas sem constituir uma importante referência partidária para o grupo.
Pode-se afirmar que essas mulheres não são passivas, apesar de empobrecidas e inseridas em um ciclo reprodutor de pobreza. Ao relatar sua relação com o local de moradia atual, $67 \%$ delas revelam uma satisfação relativa, pois trazem sempre uma comparação com uma situação pior em relação à qual se encontram. Em geral, viviam em habitações improvisadas, moravam de favor na casa de parentes ou ainda em locais alugados e, agora, sentem-se conquistadoras de sua própria habitação, por mais precária que ela seja, o que significa um avanço para elas. Ainda que constrangidas pelo contexto socioespacial de pobreza e exclusão de direitos básicos, as mulheres aqui investigadas vivenciam um espaço paradoxal, como argumenta Rose (1993). Estão à margem das configurações de direitos iguais. Marginalização promovida pelo enlace espacial e as características normativas de gênero. Por outro lado, ao resistirem e lutarem, rompem com a míope visão vitimizadora e tencionam os centros das configurações sociosespaciais.

As mulheres realizam opções que as colocam em situação de desvantagem em relação aos homens e esse fato é resultado de longa trajetória de constituição das relações de gênero mediadas pelo espaço-tempo. Um elemento interessante é o desafio da formação escolar, visto como mais necessária para os homens do que para as mulheres. Embora o grupo focal escolhido possua um perfil de pequena escolaridade formal, $58,5 \%$ das mulheres desejam voltar a estudar e, destas, $75 \%$ acreditam que o estudo Ihes traria melhores oportunidades de trabalho e renda, como podemos ver no relato que segue:

O primeiro, não me dava, mais o segundo me dava totalmente a liberdade, ele confiava né mim. Agora o primeiro, não. Ele dizia... pra quê mulher estudá, lugar de mulher é na cozinha, portanto que eu parei de estudá quando fui morá com ele, né. Ele dizia que era uma coisa que não ia me trazê benefício nenhum, só que agora o meu arrependimento, né... agora que chegô. Por causa de eu não ter o $1^{\circ}$ grau, eu perdi muitos emprego, até pra faxineira assim, né, zeladora, mais eu vô consegui. ${ }^{6}$

O relato acima é comum nos discursos das mulheres chefes de família que sofreram ou ainda sofrem um controle de seus companheiros e, além disso, fazem concessões da sua inserção no ambiente escolar em favor de seus filhos. Mesmo acreditando melhorar suas condições socioespaciais com maior escolaridade, essas mulheres priorizam a maternagem,

6 Depoimento de uma chefe de família residente no Condomínio Social PAI - Ponta Grossa/PR. 
adequando-se ao desempenho do papel de "seres do afeto e sentimento", enquanto os homens, em geral, não abrem mão do seu papel da esfera da produção e no espaço público. Afonso (1995) argumenta que essas diferentes socializações dos gêneros se desdobram em um universo contratual não explícito, simbólico e cultural e que organiza o mundo hierarquicamente.

O grupo focal estudado, mulheres chefes de família de baixa renda, possui condições socioespaciais desfavoráveis com inexpressivos rendimentos, acompanhadas de crianças em idade escolar e de espacialidades precárias em infra-estrutura, que tende a provocar o crescimento da pobreza urbana. É esse quadro caótico que gerou a força política do Orçamento Participativo em Ponta Grossa e, embora não haja referência explícita de reivindicações de gênero, houve uma luta feminina pelo acesso aos bens urbanos que deve ser ressaltada.

Embora esquecidas e invisíveis aos olhos do Estado e dos partidos políticos, elas possuem potencial de luta. Se, por um lado, o desenvolvimento dos papéis de gênero as colocou em posição menos competitiva no acesso aos bens urbanos, como já explicitado anteriormente, ancorando suas possibilidades numa pseudo-arena de igualdade em que se esconde uma velada e sutil coerção sustentada fortemente pela relação entre questões de gênero(s) espacializadas, por outro lado, é este mesmo papel que as coloca em situação de vantagem no conhecimento das necessidades da periferia. Isso se revelou na pressão que elas exerceram na estrutura organizacional do Orçamento Participativo, quando conseguiram priorizar as reivindicações ligadas ao universo da reprodução familiar: saúde e educação.

Dados os aspectos discutidos neste artigo referentes à participação política feminina na periferia urbana de Ponta Grossa e sua assimétrica inserção no âmbito político e no consumo do que é produzido no espaço urbano, destacamos a dificuldade de se dar visibilidade a esse fenômeno a partir de uma análise do espaço geográfico feita pelo olhar de uma ciência masculina e branca. É nesse sentido que nos aliamos à reflexão de Silva $(2005,2003)$, ao apontar para a necessidade do rompimento do discurso masculino na geográfica brasileira, considerando que não é possível dar visibilidade à mulher a partir de categorias masculinas. É então que a autora discute a proposta teórica de Rose (1993) de um espaço geográfico de caráter paradoxal, como categoria de análise e de luta política, aportada pelo conceito de gênero, conforme citado no início deste artigo.
Enquanto o conceito gênero é representação mantida pela força dos sujeitos que mobilizam maior poder no processo de luta simbólica, o espaço geográfico paradoxal trabalha com a noção de fronteiras, em que o sujeito possui uma plurilocalidade e uma multidimensionalidade em um tenso embate entre centro e margem.

O ser mulher, homem, homossexual ou transgênero não comporta uma unívoca identidade, mas são interseccionados por classe, etnia, religiosidade, entre outros aspectos. As características de multidimensionalidades e plurilocalidades são precedidas pelo movimento. Exemplificando, numa configuração de poder branco/ masculino e cristão, a mulher branca ocupa o centro da configuração, mas a mesma mulher, ao exercitar uma outra religiosidade e não "ser homem" no processo relacional de construção do gênero, ocupa uma posição de margem. Então centro e margem oscilam e podem constituir inúmeras configurações no espaço-tempo. Mas é no movimento que se nota que centro e margem estão simultaneamente juntos e separados, o que caracteriza a fronteira não como limite, mas como possibilidade de instituição de um novo.

\section{CONSIDERAÇÕES FINAIS}

Este texto explorou as intersecções dos espaços públicos e privados enquanto instâncias componentes das ações de luta por parte das mulheres na cidade de Ponta Grossa/PR, visando acesso à cidade, tendo como referência de análise os grupos focais constituídos. Discutiram-se as interiorizações dos papéis sociais de gênero enquanto limites e potencialidades às disputas políticas.

Em uma visão respaldada na política tradicional, há uma clássica invisibilidade da mulher. Por outro lado, a mesma mulher configura-se no centro da política de base comunitária. É na política de base comunitária que se espacializam as trajetórias individuais e coletivas, e que estão dispostos os serviços urbanos de necessidade imediata da reprodução familiar. A mulher responsável pela reprodução da geração secundariza em um primeiro momento sua inserção política. Concomitantemente, os seus papéis sociais de gênero as potencializam como privilegiadas atrizes políticas por suas específicas produções do espaço urbano. Dessa forma, essa plurilocalidade que oscila entre centro e margem gera um movimento ávido por ser potencializado. 


\section{REFERÊNCIAS}

AFONSO, Lucia. Gênero e processo de socialização em creches comunitárias. Revista Cadernos de Pesquisa, São Paulo, n. 93, p. 12-21, maio 1995.

ANYON, Jean. Interseções de gênero e classe: acomodação e resistência de mulheres e meninas às ideologias de papéis sexuais. Cadernos de Pesquisa, São Paulo, n. 73, p.13-25, maio 1990.

BADINTER, Elizabeth. Um amor conquistado: o mito do amor materno. 5. ed. Rio de Janeiro: Nova Fronteira, 1985. 369 p.

BUTLER, Judith. Problemas de gênero: feminismo e subversão da identidade. Rio de Janeiro: Civilização Brasileira, 2003. $236 \mathrm{p}$.

CENSO DEMOGRÁFICO. Instituto Brasileiro de Geografia e Estatística: Rio de Janeiro, 2000.

CORRÊA, Roberto Lobato. A dimensão cultural do espaço: alguns temas. Espaço e Cultura, Rio de Janeiro, UERJ, n. 1. p. 1-22, out. 1995.

$94 \mathrm{p}$.

O espaço urbano. 4. ed. São Paulo: Ática, 2003a.

A geografia cultural e o urbano. In: CORRÊA, Roberto Lobato; ROSENDHAL, Zeny (Org.). Introdução à geografia cultural. Rio de Janeiro: Bertrand Brasil, 2003b. p.167-186.

COSGROVE, Denis. Geografia cultural do milênio. In: CORRÊA, Roberto Lobato; ROSENDHAL, Zeny (Org.). Manifestações da cultura no espaço. Rio de Janeiro: UERJ, 1999. p.17-46.

DUNCAN, James Stuart; DUNCAN, Nancy. Reconceitualizando a idéia de cultura em Geografia: uma resposta a Don Mitchell. Espaço e Cultura, Rio de Janeiro; UERJ, n. 8, p. 63-67, ago./ dez. 1999.

GIDDENS, Antony. Para além da esquerda e da direita. São Paulo: UNESP, 1996. 296 p.

GOTTDIENER, Mark. A produção social do espaço urbano. São Paulo: EDUSP, 1993. 310 p.

JOVCHELOVITCH, Sandra. Representações sociais e esfera pública: a construção simbólica dos espaços públicos no Brasil. Petrópolis, Vozes, 2000. 231 p.

MCDOWELL, Linda. Gender, Identity and Place: Understanding Feminist Geographies. Minneapolis: University of Minnesota Press, 1999. 283 p.

MIGNOLO, Walter D. Os esplendores e as misérias da "ciência": colonialidade, geopolítica do conhecimento e pluriversalidade epistémica. In: SANTOS, Boaventura de Souza. (Org.). Conhecimento prudente para uma vida decente. São Paulo: Cortez, 2004. p. 667-709.
MORIN, Edgar. Problemas de uma epistemologia complexa. In: (Org.). O problema epistemológico da complexidade. Sintra - Portugal: Europa-América, 1996. p. 13-34. Coleção Biblioteca Universitária.

PERROT, Michelle. O gênero da cidade. História \& Perspectivas, Uberlândia, n. 24, p. 9-26, jan./jun. 2001.

PROCHNER, Marcilene. Recente feminização da periferia de baixa renda em Ponta Grossa-PR: análise da atuação da PROLAR. Monografia (Especialização em Geografia e Desenvolvimento Regional), sob orientação de SILVA, Joseli Maria - UFPG, Ponta Grossa, 2005.79 f.

RIBEIRO, Matilde. Orçamento participativo: panorama geral e referenciais sobre gênero e raça. Revista Proposta, Rio de Janeiro, FASE, n. 84/85, p. 70-82, mar./ago. 2000.

ROSE, Gillian. Feminism \& Geography: The limits of Geographical Knowledge. Cambridge: Polity Press, 1993. $205 \mathrm{p}$.

ROUGEMONT, Denis de. História do amor no Ocidente. 2. ed. São Paulo: Ediouro, 2003. 543 p.

SÁ, Celso Pereira. A construção do objeto de pesquisa em representações sociais. Rio de Janeiro: UERJ, 1998. 110 p.

SARTI, Cinthia. A. Reciprocidade e hierarquia: relações de gênero na periferia de São Paulo. Cadernos de Pesquisa, São Paulo, n. 70, p. 38-46, ago. 1989.

SILVA, Joseli Maria. Análise do espaço sob a perspectiva do gênero: um desafio para a geografia cultural brasileira. In: CORREAA, Roberto Lobato; ROSENDHAL, Zeny (Org.). Geografia: temas sobre cultura e espaço. Rio de Janeiro: UERJ, 2005. p. 173-189.

. Um ensaio sobre as potencialidades do uso do conceito de gênero na análise geográfica. Revista de História Regional, Ponta Grossa, Dep. História, UEPG, v. 8, n. 1, p. 31-45, verão 2003.

SMITH, Susan. Teoria política e geografia humana. In: GREGORY, Derek; MARTIN, Ron; SMITH, Graham (Org.). Geografia humana: sociedade, espaço e ciência social. Rio de Janeiro: Zahar, 1996. p. 65-89. 